\title{
Inhibition of SARS-CoV-2 entry through the ACE2/TMPRSS2 pathway: a promising approach for uncovering early COVID-19 drug therapies
}

\author{
Georgia Ragia $^{1}$ (I) $\cdot$ Vangelis G. Manolopoulos ${ }^{1,2}$ (D) \\ Received: 21 May 2020 / Accepted: 16 July 2020 / Published online: 21 July 2020 \\ (C) Springer-Verlag GmbH Germany, part of Springer Nature 2020
}

\begin{abstract}
Aim The COVID-19 pandemic caused by infection with the novel coronavirus SARS-CoV-2 is urging the scientific community worldwide to intense efforts for identifying and developing effective drugs and pharmacologic strategies to treat the disease. Many of the drugs that are currently in (pre)clinical development are addressing late symptoms of the disease. This review focuses on potential pharmacologic intervention at an early stage of infection which could result in less-infected individuals and less cases with severe COVID-19 disease due to reduced virus entry into the cells.

Method We scanned the literature for evidence on drugs that target the virus entry machinery into host cells and consist mainly of ACE2 and TMPRSS2, as well as other cellular molecules regulating ACE2 expression, such as ADAM-17 and calmodulin. Results Several drugs/drug classes have been identified. Most of them are already used clinically for other indications. They include recombinant soluble ACE2, indirect ACE2 modulators (angiotensin receptor blockers, calmodulin antagonists, selective oestrogen receptor modifiers), TMPRSS2 inhibitors (camostat mesylate, nafamostat mesylate, antiandrogens, inhaled corticosteroids) and ADAM-17 enhancers (5-fluorouracil).

Conclusion Several agents have potential for prophylactic and therapeutic intervention at the early stages of SARS-CoV-2 infection and COVID-19 disease and they should be urgently investigated further in appropriate preclinical models and clinical studies.
\end{abstract}

Keywords SARS-CoV-2 COVID-19 $\cdot$ ACE2 $\cdot$ TMPRSS2 $~ A D A M-17 \cdot$ Calmodulin antagonists $\cdot$ Angiotensin receptor blockers $\cdot$ Antiandrogens $\cdot$ Camostat mesylate $\cdot$ Nafamostat mesylate $\cdot$ SERMs $\cdot 5$-fluorouracil $\cdot$ Inhaled corticosteroids

\section{Introduction}

Severe acute respiratory syndrome coronavirus-2 (SARSCoV-2) has emerged in December 2019 as the newest member of a family of coronaviruses $(\mathrm{CoV})$ that invade the respiratory tract of mammals including humans. In many of the humans it infects, SARS-CoV-2 causes mild to severe respiratory tract disease which has been named coronavirus disease 19 (COVID-19). The two previously known members of this family having the ability to infect humans were SARS-CoV

Vangelis G. Manolopoulos

emanolop@med.duth.gr

1 Laboratory of Pharmacology, Medical School, Democritus University of Thrace, Dragana Campus, 68100 Alexandroupolis, Greece

2 Clinical Pharmacology and Pharmacogenetics Unit, Academic General Hospital of Alexandroupolis, Alexandroupolis, Greece and the Middle East respiratory syndrome coronavirus (MERS-CoV).

The mechanism of interaction of SARS-CoV-2 with the human cells it invades is similar to SARS-CoV [1-3]. The virus binds to membrane-bound human angiotensin-converting enzyme 2 (ACE2) to enter the host cells. This interaction with ACE2 is mediated via the spike (S) glycoprotein on SARS-CoV-2 surface. During infection, the $\mathrm{S}$ protein is cleaved into subunits, $\mathrm{S} 1$ and S2. S1 contains the receptor-binding domain (RBD) which allows SARS-CoV-2 to directly bind to the peptidase domain of ACE2. S2 then likely plays a role in membrane fusion. Initial spike protein priming relies upon human transmembrane protease, serine 2 (TMPRSS2) and is essential for entry of SARS-CoV-2 [4]. Furthermore, the ectodomain of ACE2 can be shed endogenously by the disintegrin metalloproteinase 17 (ADAM-17) [5]. This soluble form of ACE2 lacks the membrane anchor and circulates in small amounts in the blood. Finally, 
calmodulin (CALM) has been shown to interact with ACE2 and inhibit shedding of its ectodomain [6]. A summary of the ACE2/TMPRSS2 pathway and its interaction with SARS-CoV-2 is depicted in Fig. 1.

Since SARS-CoV-2 has emerged, it is causing a major disruption of economic and social life of individuals worldwide due to its high infective potential which has resulted in more than 11 million confirmed cases of infected individuals as of July 3rd, 2020, and more than 525,000 deaths worldwide. In approximately $20 \%$ of these cases, the infection spreads to the lungs and other organs of the body and establishes COVID-19. No drug so far has been formally approved for the disease. Most of the drugs that have been used or are still used to COVID19 patients on circumstantial evidence as well as the ones that are currently in (pre)clinical development are addressing late symptoms of the disease. It had been hypothesised that pharmacologic intervention at an early stage of infection may result in much less cases of individuals with severe COVID-19 disease due to reduced virus entry into the cells. Accordingly, ACE2, and the two enzymes ADAM-17 and CALM (that are known to be implicated in its regulation) as well as TMPRSS2, constitute attractive targets for pharmacologic intervention to achieve this goal [7]. We present here several drug classes/molecules that interfere with elements of the ACE2/TMPRSS2 virus entry pathway and may reduce the incidence and severity of COVID-19. These include mostly drugs already in the market and used for various indications, but also some newly developed agents. The specific sites and mode of action of each of these drugs/ drug classes are shown in Fig. 2.

\section{Direct ACE2 modulators}

ACE2, discovered nearly 20 years ago, is an enzyme that converts angiotensin I to angiotensin 1-9, a peptide of unknown function, and angiotensin II to angiotensin 17 , a vasodilator. The encoded protein is a functional receptor for the $\mathrm{S}$ glycoprotein of the human SARS-CoV, HCoV-NL63 and SARS-CoV-2 [1, 7, 8]. ACE2 is the critical receptor for SARS-CoV-2 infection. Currently, it appears as a promising pharmacologic target and it has
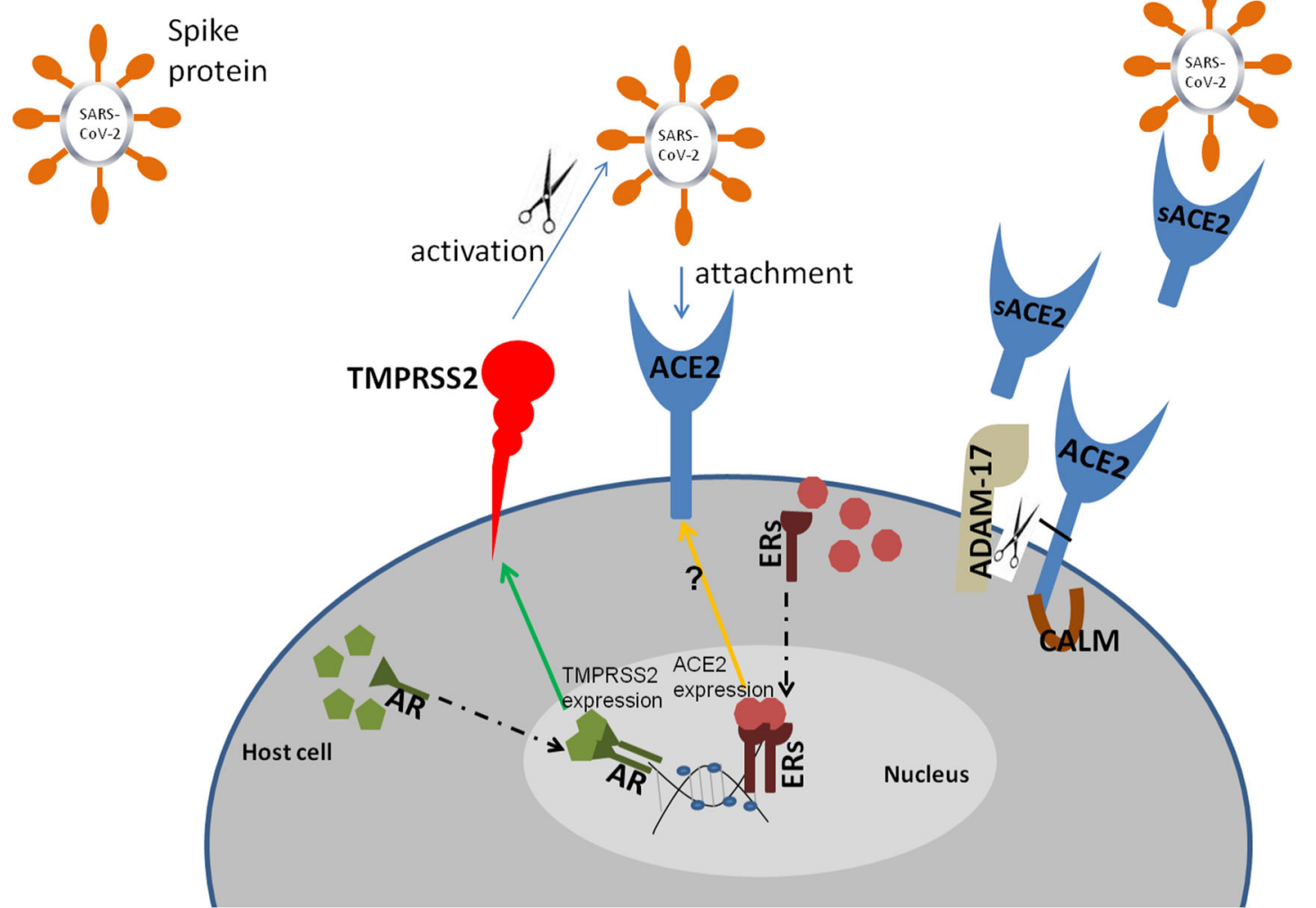

Androgens

Estrogens

Fig. 1 The ACE2/TMPRSS2 pathway and its interaction with SARSCoV-2. SARS-CoV-2 binds to membrane-bound ACE2 to enter the host cells. This interaction with ACE2 is mediated via the spike glycoprotein on SARS-CoV-2 surface. Spike protein priming is essential for entry of SARS-CoV-2 and relies upon TMPRSS2. The ectodomain of ACE2 can be shed by ADAM-17 generating the soluble form of ACE2 (sACE2). CALM interacts with ACE2 and inhibits shedding of its ectodomain. AR activation up-regulates TMPRSS2 expression, whereas ER activation potentially regulates ACE2 expression. Upregulation is represented by green. Potential up- or down-regulation is represented by orange. AR, androgen receptor; ACE2, angiotensin-converting enzyme 2; ADAM-17, disintegrin metalloproteinase 17; CALM, calmodulin; ERs, oestrogen receptors; sACE2, soluble ACE2; TMPRSS2, transmembrane protease, serine 2 


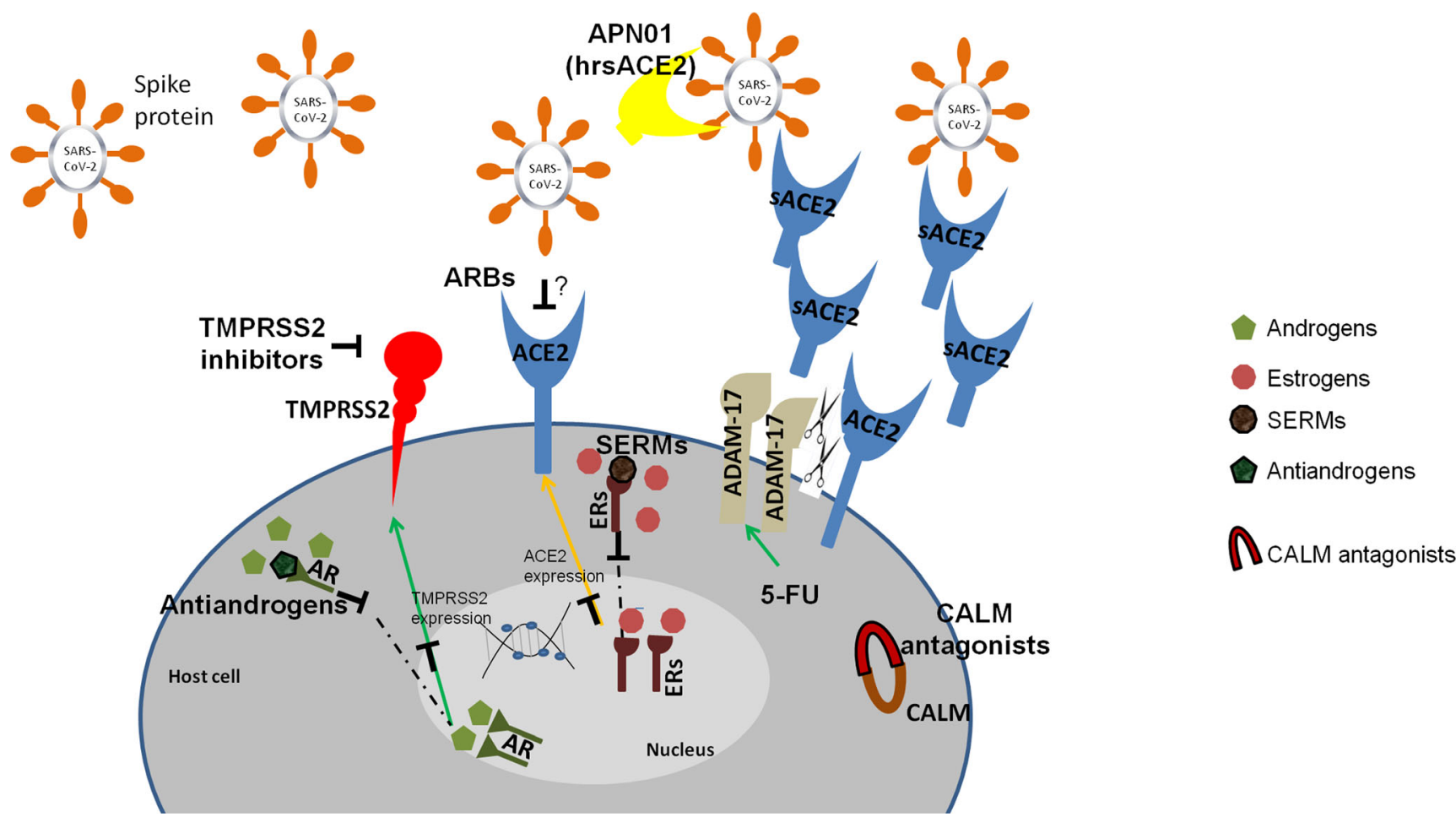

Fig. 2 COVID-19 early stage pharmacologic intervention targeting SarsCoV-2 cell entry through the ACE2/TMPRSS2 pathway. Mechanisms of action of pharmacologic agents acting on the ACE2/TMPRSS2 pathway that could prevent Sars-CoV-2 entry to host cell are summarized. These agents include (i) directly acting agents such as hrsACE2 that imitates the soluble human enzyme ACE2; (ii) indirect ACE2 modulators including (a) ARBs that potentially block the binding and hence, attachment of SARS-CoV-2 to ACE2-expressing cells, (b) calmodulin antagonists that inhibit CALM-ACE2 interaction and increase the release of the ACE2 ectodomain, and (c) SERMs that potentially modulate ACE2 expression; (iii) TMPRSS2 inhibitors (camostat mesylate, nafamostat mesylate, antiandrogens, and potentially ICS if verified in different studies) that inhibit the S-mediated membrane fusion of SARS-CoV-2; and (iv) ADAM-17 enhancers (conjugated estrogens, 5-fluorouracil) that activate ADAM-17 and increase the release of the sACE2 through ACE2 ectodomain shedding. Upregulation is represented by green. Potential upor down-regulation is represented by orange. Inhibition is represented by -. AR, androgen receptor; ACE2, angiotensin-converting enzyme 2; ADAM-17, disintegrin metalloproteinase 17; ARBs, angiotensin receptor blockers; CALM, calmodulin; ERs, oestrogen receptors; ICS, inhaled corticosteroids; TMPRSS2, transmembrane protease, serine 2; SERMs, selective oestrogen receptor modulators; 5-FU, 5-fluorouracil been proposed that inhibiting this interaction could be a valid strategy for treating patients with COVID-19. Although attached ACE-2 may allow SARS-CoV-2 to enter cells, its free circulating forms may inactivate SARS$\mathrm{CoV}-2$ by attaching themselves to the virus and stopping coupling to membrane ACE2 receptor and consequent entry into pulmonary endothelial cells. Recombinant soluble ACE2 (hrsACE2) has already been tested in phase 1 and phase 2 clinical trials aiming to enhance ACE2 activity in human diseases with pathologically elevated Ang1-8 [9] and in acute respiratory distress syndrome [10]. APN01, a rhACE2 designed to imitate the human enzyme ACE2 so that SARS-CoV-2 can no longer infect the cells, is currently in phase 2 clinical trial by the European biotech company Apeiron Biologics (NCT04335136, registered on April 6, 2020). The trial aims to compare APN01 to placebo in up to 200 severely infected COVID-19 patients at 10 sites. In addition, it was recently shown that clinical grade hrsACE2 reduces SARS-CoV-2 recovery from Vero-E6 cells by a factor of $1000-5000$ [11].

\section{Other ACE2 modulators}

\section{Angiotensin receptor blockers}

Treatment of hypertension, cardiac failure and other indications of the cardiovascular system relies on drugs targeting renin-angiotensin axis, such as ACE inhibitors (ACEi) and angiotensin II receptor blockers (ARBs). Discussion on whether or how these drugs impact COVID-19 is ongoing. A hypothesis put forward on possible upregulation of ACE2 membrane expression leading to increased susceptibility to SARS-Cov2 infection and COVID-19 disease severity in patients treated with ACEi and ARBs was not supported by findings of recent studies [12-14]. In contrast, evidence is emerging pointing towards a beneficial effect of ARBs. A retrospective study in hypertensive Chinese COVID-19 patients was recently published showing a possible beneficial relation between the use of ARBs/ACEi and both severity of disease and reduced deaths [15]. Unfortunately, no discriminative information between ARBs and ACEi was reported in 
this study, neither between individual ARBs. Interestingly, network proximity analysis uncovered irbesartan as the drug topping a list of 16 drugs (out of almost 3000 FDA-approved drugs that were included in the analysis) showing a significant association between irbesartan's targets and $\mathrm{HCoV}$-associated host proteins in the human interactome [16]. Additionally, a phase 2 prospective clinical trial has been initiated by the University of Minnesota, testing losartan for its beneficial effect when prescribed in COVID-19 patients within $24 \mathrm{~h}$ of hospital admission or a positive test result, whichever is later (NCT04312009, registered on March 17, 2020). It should be kept in mind that (a) the various ARBs have significant structural differences and (b) they also have many functional differences that are not mediated by blockade of angiotensin type 1 receptor $[17,18]$. Thus, it is necessary to study the most promising ones (discussed above) individually for their potential beneficial effect on SARS-CoV-2 infection/COVID-19.

\section{Calmodulin antagonists}

Another class of drugs that interact with ACE2 by inhibiting the shedding of its ectodomain are calmodulin antagonists. Calmodulin antagonists inhibit CALM-ACE2 interaction and increase the release of the ACE2 ectodomain in a doseand time-dependent manner [6]. Several marketed drugs, especially psychotropic medications, including melatonin, trifluoperazine, perphenazine, pimozide and amitriptyline, are known to inhibit calmodulin interaction with its target enzymes $[19,20]$. It should be noted that melatonin was also identified as one of the top 16 network-predicted repurposable drugs showing a significant association between their targets and $\mathrm{HCoV}$-associated host proteins in the human interactome [16]. The potential benefits of melatonin in the attenuation of COVID-19 based on its antioxidant, anti-inflammatory and immunomodulatory properties have been recently summarized [21]. The prophylactic use of melatonin against SARS$\mathrm{CoV}-2$ is currently assessed in healthcare workers exposed to the virus in their clinical practice [Efficacy of Melatonin in the Prophylaxis of Coronavirus Disease 2019 (COVID-19) Among Healthcare Workers. (MeCOVID), NCT04353128, registered on April 20, 2020]. Additionally, melatonin effectiveness as an add-on treatment method along with a standard antiviral drug regimen in patients with severe COVID-19 will be evaluated in an interventional clinical study due to start soon (Evaluation of Therapeutic Effects of Melatonin by Inhibition of NLRP3 Inflammasome in COVID19 Patients, NCT04409522, registered on June 1, 2020).

Evidence exists that the selective oestrogen receptor modifiers (SERMs) tamoxifen and toremifene are also calmodulin antagonists [22, 23]. Interestingly, both drugs have been shown to inhibit MERS-CoV and SARS-CoV [24], and also to exhibit antiviral activity against $\mathrm{HIV}, \mathrm{HCV}$ and $\mathrm{EBOV}$ [25]. In addition, in network proximity analysis, toremifene alone or in combination with emodin (an experimental drug for the treatment of polycystic kidney disease) offered a potential therapeutic approach for SARS-CoV-2 [16]. For raloxifene, another member of SERMs class, there are no reports on its effect on calmodulin. Nevertheless, it appears as the first SERM for which researchers required access to clinical trials for use in asymptomatic or COVID-19 patients with mild symptoms [26].

It is plausible that SERMs also affect ACE2 expression. Upon binding to the oestrogen receptors (ERs), oestrogen exerts complex tissue-specific regulation over the components of the renin-angiotensin-aldosterone system. Among ACE2 regulatory regions, there are many oestrogen receptor binding motifs. Through binding to ER $\alpha$, estradiol significantly increases ACE2 expression in human atrial myocardium [27], whereas ACE2 expression is down-regulated in kidneys and no effect was found in the lung [28]. Overall, no clear picture is emerging and the role (if any) of oestrogen in COVID-19 remains to be elucidated. One study went to the opposite direction hypothesising that oestrogen receptor activation with conjugated estrogens may be a good prevention and therapeutic strategy against COVID-19, on the basis of findings in animal experiments showing that oestrogen treatment silences the inflammatory reactions and decreases virus titres leading to improved survival rate [29].

\section{TMPRSS2 inhibitors}

TMPRSS2 gene encodes for transmembrane protease serine 2 , which is essential for viral infectivity by facilitating viruscell membrane fusions through ACE2. TMPRSS2 proteolytically cleaves and activates the $\mathrm{S}$ glycoproteins of human $\mathrm{CoV}$ and the fusion glycoproteins of other viruses such as HMPV and HPIV and is involved in proteolytic cleavage and activation of hemagglutinin (HA) protein making TMPRSS2 essential for spread and pathogenesis of influenza A virus (strains H1N1, H3N2 and H7N9). TMPRSS2 is involved in SARSCoV-2 $\mathrm{S}$ protein priming, possibly promoting viral uptake [3].

Camostat Mesylate is a potent TMPRSS2 inhibitor and has been shown to block SARS-CoV cell entry mechanism. In $\mathrm{BALB} / \mathrm{c}$ mice infected with SARS-CoV, camostat, dosed at concentrations similar to the clinically achievable concentration in humans, significantly reduced mortality following SARS-CoV infection [30]. Hoffmann and colleagues recently confirmed that this drug effectively blocks also SARS-CoV-2 entry into lung cells [3]. Camostat is used to treat chronic pancreatitis in Japan; it is thus readily available and represents an exciting potential therapeutic agent for respiratory coronavirus infections including SARS-CoV-2. Accordingly, a phase $1 / 2$ clinical trial has recently been initiated in Denmark, entitled "The Impact of Camostat Mesilate on COVID-19 Infection: An Investigator-initiated Randomized, Placebo-controlled, Phase IIa Trial" assessing the impact of 
Camostat Mesylate, on the course of COVID-19 (NCT04321096, registered on March 25, 2020). A different clinical trial (Camostat Mesylate in COVID-19 Outpatients, NCT04353284, registered on April 20, 2020) is currently recruiting patients aiming to identify whether camostat could reduce the viral burden in the upper respiratory tract and therefore forestall complications of SARS-CoV-2 infection and reduce transmission when given to outpatients within 2 days of being notified of their positive COVID-19 test result.

Another TMPRSS2 inhibitor with therapeutic potential for treatment of COVID-19 is nafamostat mesylate, an FDAapproved drug for indications unrelated to corona virus and used in Asian countries as a short-acting anticoagulant. Nafamostat was identified as a potent inhibitor of Smediated membrane fusion of MERS-CoV and blocked MERS-CoV infection in vitro [31]. A recent study reported that nafamostat inhibited SARS-CoV-2 entry into host cells with roughly 15 -fold higher efficiency than camostat, with an $\mathrm{EC}_{50}$ in the low nanomolar range. In addition, it blocked SARS-CoV-2 infection of human lung cells with markedly higher efficiency than camostat mesylate [32]. Thus, this drug may also be worth investigating for its ability to reduce SARS-CoV-2 infective capacity. Currently, two clinical trials are scheduled to start recruiting patients aiming to evaluate the clinical efficacy of nafamostat mesylate in adult patients hospitalized with COVID-19 pneumonia (Clinical Efficacy of Nafamostat Mesylate for COVID-19 Pneumonia, NCT04418128, registered on June 5, 2020) and its effect on lung function deterioration and need for intensive care admission in COVID-19 patients [Efficacy of Nafamostat in Covid19 Patients (RACONA Study), NCT04352400, registered on April 20, 2020). Overall, TMPRSS2 is essential for SARSCoV-2 infectivity and appears as a promising target for drug therapy of COVID-19 at an early stage.

Interestingly, the human TMPRSS2 gene promoter has a 15-bp androgen response element. The upregulation of TMPRSS2 mRNA by androgens appears to be mediated by the androgen receptor [33]. This raises the possibility that androgens may have a role in SARS-CoV-2 infectivity and COVID-19 course of disease. Some indirect evidence points to this direction. A constant characteristic of the corona virus pandemic is that more males than females get infected (with a ratio of approximately 60/40). Also, more infected males proceed to develop severe disease, get hospitalized and die. To explain the fact that males present with more severe COVID19 symptoms, a recent study suggested a potential involvement androgens based on the preliminary epidemiologic observation of high frequency of male pattern hair loss among admitted COVID-19 patients [34]. Stronger evidence in this direction was recently reported by a group in Italy [35]. They extracted data from 9280 subjects (4532 males) with laboratory-confirmed SARS-CoV-2 infection from 68 hospitals in the area of Veneto. Overall, males developed more severe complications, were hospitalized more frequently and had worse clinical outcomes than females. Comparing the total number of SARS-CoV-2 positive cases, prostate cancer patients receiving androgen-deprivation therapy (ADT) had a significantly lower risk of SARS-CoV-2 infection compared to patients who did not receive ADT (OR 4.05; 95\% CI 1.5510.59). They concluded that, while cancer patients overall have an increased risk of SARS-CoV-2 infections compared to non-cancer patients, prostate cancer patients receiving ADT appear to be partially protected from SARS-CoV-2 infections [35].

Several classes of drugs exhibit antiadrogenic activity and are in clinical use for ADT, including androgen receptor blockers such as bicalutamide and enzalutamide, androgen synthesis inhibitors, and antigonadotropins [34]. Furthermore, new antiandrogens that target testosterone synthesis (abiraterone acetate and seviteronel) or androgen receptor nuclear translocation (enzalutamide, apalutamide and darolutamide), as well as combined therapies (galeterone) have been recently developed and may function to better target androgen-responsive cells in combination with ADT. These agents may down-regulate TMPRSS 2 mRNA and expression resulting in less entry of SARS-CoV-2 entry into cells and thus could arise as promising therapeutic tools in early SARS-CoV-2 infection and COVID-19. This hypothesis will soon be tested: two clinical trials investigating the potential protective role of the antiandrogens dutasteride and bicalutamide in SARS-CoV-2 infection are about to start [Anti-Androgen Treatment for COVID-19, NCT04446429, registered on June 24, 2020; Trial to Promote Recovery From COVID-19 With Ivermectin or Endocrine Therapy (RECOVER), NCT04374279, registered on May 5, 2020).

There is some debate as to whether inhaled corticosteroids (ICS) modify the expression of ACE2 and TMPRSS2 and could thus have a role in COVID-19 therapy. A recent study has shown that in sputum cells of asthmatic patients, the use of ICS is associated with lower expression of ACE2 and TMPRSS2, warranting prospective study of ICS use as a predictor of decreased susceptibility to SARS-CoV-2 infection and decreased COVID19 morbidity [36]. On the contrary, another study has shown that ACE2, TMPRSS2 and furin gene expression in bronchial brush samples is not affected in patients with mild to moderate or severe asthma compared with healthy controls [37]. This is a topic of significant interest and intense current investigation, in view also of the beneficial effect reported recently of systemic dexamethasone use in COVID-19 patients with severe disease [38].

\section{ADAM-17 enhancers}

The ADAMs (A Disintegrin And Metalloproteinase) is a family of transmembrane and secreted proteins. ADAMs are implicated in a variety of cellular processes, including processing 
of proteins, interactions with integrin receptors and with signalling molecules. In particular, one member of this family, ADAM-17, also known as TNF $\alpha$-converting enzyme, appears to be an indispensible regulator of almost every cellular event from proliferation to migration [39, 40]. ADAM-17 is widely expressed in various tissues including bronchial epithelial cells, vascular smooth muscle cells and macrophages in the lung. The function of ADAM-17 is to cleave ectodomains of various transmembrane proteins, including ACE2. This makes it an attractive target for pharmacologic manipulation, since its stimulation could result in increased ACE2 shedding, thus higher levels of soluble ACE2 ectodomain [5], which could reduce the infectivity of the SARS-Cov-2.

Some evidence regarding pharmacologic upregulation of ADAM-17 has emerged. Estradiol was shown to enhance ADAM-17 expression and protein levels in human nonsmall cell lung cancer [41]. If confirmed in COVID-19 patients, this finding would suggest higher ACE2 shedding in female, providing a plausible partial explanation of the gender differences favouring females that clearly exist in SARSCoV-2 infectivity and COVID-19 severity course. This is in agreement with the hypothesis already mentioned for a potential role of oestrogen receptor activation with conjugated estrogens as a good prevention and therapeutic strategy against COVID-19 [29].

Also, 5-fluorouracil (5-FU), a widely used antineoplastic agent which acts as an antimetabolite, has been reported to acutely activate ADAM-17 in vitro and in vivo in models of colorectal cancer [42].

\section{Conclusions}

COVID-19 is a devastating novel disease resulting in thousands of deaths worldwide. It is essential to find therapies as quickly as possible. Since this is a novel disease, so far, no drugs have been shown to be really effective or have received approval for its therapy, with the exception of the recent conditional approval by the FDA of the antiviral agent remdesivir, to be used intravenously for hospitalized patients with "severe disease," such as those who need supplemental oxygen or ventilators to breathe. Most drug use on patients is done empirically and on the basis of dealing with the extensive inflammatory symptoms that appear at late stages of the disease. It is of major importance to identify agents that can act early at the level of virus entry in the cell, ideally either inhibiting entry or reducing the virus load that makes it in to the cell. Intensive efforts by several groups worldwide are in full swing to discover novel agents, but this may take significant time since new drugs have to go through lengthy preclinical and clinical safety testing. A quicker approach is to look for drugs already approved for human use, since they have undergone complete safety testing and their safety profile, as well as pharmacokinetic and pharmacodynamics properties, are well established.

We have presented here mechanistic-driven hypotheses supported by emerging evidence on several pharmacologic agents (most of them already used clinically for other indications) which are known to interfere with elements of the virus entry pathway. These include (i) human recombinant ACE2 that increases available sACE2, (ii) the angiotensin receptor blockers irbesartan and losartan, (iii) calmodulin antagonists such as melatonin and certain other psychotropic medications and the selective oestrogen receptor modifiers tamoxifen and toremifene, (iv) the TMPRSS2 inhibitors camostat mesylate, nafamostat mesylate and several antiandrogens, and finally (v) the ADAM-17 enhancers 5-fluorouracil and conjugated estrogens. We suggest that these agents should be investigated further in appropriate preclinical and clinical disease models for their potential as promising prophylactic and therapeutic interventions in early SARS-CoV-2 infection. Since this would be a new indication of these drugs and may result from different mechanism of action, it will be necessary to establish the appropriate dose range and dosing schedules for the new indication for each of the tested agents. Finally, it should be kept in mind that all these approaches may exert benefit only if applied in the early phase of SARS-CoV-2 infection and COVID-19. Thus, for such therapeutic approaches to be effective, early detection of virus infection and drug therapy start will be required, as later in the disease course, such interventions may be overwhelmed by the inflammatory process.

Authors' contributions Vangelis G. Manolopoulos conceived the idea for the article. Georgia Ragia and Vangelis G. Manolopoulos performed the literature search and drafted the manuscript.

Funding information Not applicable.

Data availability Not applicable.

\section{Compliance with ethical standards}

Conflict of interest The authors declare that they have no conflict of interest.

Ethics approval Not applicable.

Consent to participate Not applicable.

Consent for publication Not applicable.

Code availability Not applicable.

\section{References}

1. Li W, Moore MJ, Vasilieva N, Sui J, Wong SK, Berne MA, Somasundaran M, Sullivan JL, Luzuriaga K, Greenough TC, 
Choe H, Farzan M (2003) Angiotensin-converting enzyme 2 is a functional receptor for the SARS coronavirus. Nature. 426(6965): 450-454. https://doi.org/10.1038/nature02145

2. Li W, Zhang C, Sui J, Kuhn JH, Moore MJ, Luo S, Wong SK, Huang IC, Xu K, Vasilieva N, Murakami A, He Y, Marasco WA, Guan Y, Choe H, Farzan M (2005) Receptor and viral determinants of SARS-coronavirus adaptation to human ACE2. EMBO J 24(8): 1634-1643. https://doi.org/10.1038/sj.emboj.7600640

3. Hoffmann M, Kleine-Weber H, Schroeder S, Krüger N, Herrler T, Erichsen S, Schiergens TS, Herrler G, Wu NH, Nitsche A, Müller MA, Drosten C, Pöhlmann S (2020) SARS-CoV-2 cell entry depends on ACE2 and TMPRSS2 and is blocked by a clinically proven protease inhibitor. Cell 181(2):271-280.e8. https://doi.org/10. 1016/j.cell.2020.02.052

4. Sanders JM, Monogue ML, Jodlowski TZ, Cutrell JB (2020) Pharmacologic treatments for coronavirus disease 2019 (COVID19): a review. JAMA. https://doi.org/10.1001/jama.2020.6019

5. Lambert DW, Yarski M, Warner FJ, Thornhill P, Parkin ET, Smith AI, Hooper NM, Turner AJ (2005) Tumor necrosis factor-alpha convertase (ADAM17) mediates regulated ectodomain shedding of the severe-acute respiratory syndrome-coronavirus (SARS$\mathrm{CoV}$ ) receptor, angiotensin-converting enzyme-2 (ACE2). J Biol Chem 280(34):30113-30119. https://doi.org/10.1074/jbc. M505111200

6. Lambert DW, Clarke NE, Hooper NM, Turner AJ (2008) Calmodulin interacts with angiotensin-converting enzyme-2 (ACE2) and inhibits shedding of its ectodomain. FEBS Lett 582(2):385-390. https://doi.org/10.1016/j.febslet.2007.11.085

7. Zhang H, Penninger JM, Li Y, Zhong N, Slutsky AS (2020) Angiotensin-converting enzyme 2 (ACE2) as a SARS-CoV-2 receptor: molecular mechanisms and potential therapeutic target. Intensive Care Med 46(4):586-590. https://doi.org/10.1007/ s00134-020-05985-9

8. Hofmann H, Pyrc K, van der Hoek L, Geier M, Berkhout B, Pöhlmann S (2005) Human coronavirus NL63 employs the severe acute respiratory syndrome coronavirus receptor for cellular entry. Proc Natl Acad Sci U S A 102(22):7988-7993. https://doi.org/10. 1073/pnas.0409465102

9. Haschke M, Schuster M, Poglitsch M, Loibner H, Salzberg M, Bruggisser M, Penninger J, Krähenbühl S (2013) Pharmacokinetics and pharmacodynamics of recombinant human angiotensin-converting enzyme 2 in healthy human subjects. Clin Pharmacokinet 52(9):783-792. https://doi.org/10.1007/s40262013-0072-7

10. Khan A, Benthin C, Zeno B, Albertson TE, Boyd J, Christie JD, Hall R, Poirier G, Ronco JJ, Tidswell M, Hardes K, Powley WM, Wright TJ, Siederer SK, Fairman DA, Lipson DA, Bayliffe AI, Lazaar AL (2017) A pilot clinical trial of recombinant human angiotensin-converting enzyme 2 in acute respiratory distress syndrome. Crit Care 21(1):234. https://doi.org/10.1186/s13054-0171823-x

11. Monteil V, Kwon H, Prado P, Hagelkrüys A, Wimmer RA, Stahl M, Leopoldi A, Garreta E, Hurtado Del Pozo C, Prosper F, Romero JP, Wirnsberger G, Zhang H, Slutsky AS, Conder R, Montserrat N, Mirazimi A, Penninger JM (2020) Inhibition of SARS-CoV-2 infections in engineered human tissues using clinical-grade soluble human ACE2. Cell. S0092-8674(20):30399-30398. https://doi.org/ 10.1016/j.cell.2020.04.004

12. Reynolds HR, Adhikari S, Pulgarin C, Troxel AB, Iturrate E, Johnson SB, Hausvater A, Newman JD, Berger JS, Bangalore S, Katz SD, Fishman GI, Kunichoff D, Chen Y, Ogedegbe G, Hochman JS (2020) Renin-angiotensin-aldosterone system inhibitors and risk of Covid-19. N Engl J Med 382:2441-2448. https:// doi.org/10.1056/NEJMoa2008975

13. Mancia G, Rea F, Ludergnani M, Apolone G, Corrao G (2020) Renin-angiotensin-aldosterone system blockers and the risk of
Covid-19. N Engl J Med 382:2431-2440. https://doi.org/10.1056/ NEJMoa2006923

14. Mehra MR, Desai SS, Kuy S, Henry TD, Patel AN (2020) Cardiovascular disease, drug therapy, and mortality in Covid-19. N Engl J Med 382:e102. https://doi.org/10.1056/NEJMoa2007621

15. Yang G, Tan Z, Zhou L, Yang M, Peng L, Liu J, Cai J, Yang R, Han J, Huang Y, He S (2020) Effects of ARBs and ACEIs on virus infection, inflammatory status and clinical outcomes in COVID19 patients with hypertension: a single center retrospective study. Hypertension. 76:51-58. https://doi.org/10.1161/ HYPERTENSIONAHA.120.15143

16. Zhou Y, Hou Y, Shen J, Huang Y, Martin W, Cheng F (2020) Network-based drug repurposing for novel coronavirus 2019nCoV/SARS-CoV-2. Cell Discov 6:14. https://doi.org/10.1038/ s41421-020-0153-3

17. Kurtz TW, Pravenec M (2008) Molecule-specific effects of angiotensin II-receptor blockers independent of the renin-angiotensin system. Am J Hypertens 21(8):852-859. https://doi.org/10.1038/ ajh.2008.202

18. Michel MC, Foster C, Brunner HR, Liu L (2013) A systematic comparison of the properties of clinically used angiotensin II type 1 receptor antagonists. Pharmacol Rev 65(2):809-848. https://doi. org/10.1124/pr.112.007278

19. Soto-Vega E, Meza I, Ramírez-Rodríguez G, Benitez-King G (2004) Melatonin stimulates calmodulin phosphorylation by protein kinase C. J Pineal Res 37(2):98-106. https://doi.org/10.1111/j. 1600-079X.2004.00141.x

20. Roufogalis BD (1985) Calmodulin antagonism. In: Marmé D (ed) Calcium and cell physiology. Springer, Berlin, Heidelberg, pp 148169

21. Zhang R, Wang X, Ni L, Di X, Ma B, Niu S, Liu C, Reiter RJ (2020) COVID-19: melatonin as a potential adjuvant treatment. Life Sci 250:117583. https://doi.org/10.1016/j.lfs.2020.117583

22. Lam HY (1984) Tamoxifen is a calmodulin antagonist in the activation of cAMP phosphodiesterase. Biochem Biophys Res Commun 118(1):27-32. https://doi.org/10.1016/0006-291x(84) 91062-3

23. Butts A, Koselny K, Chabrier-Roselló Y, Semighini CP, Brown JC, Wang X, Annadurai S, DiDone L, Tabroff J, Childers WE Jr, Abou-Gharbia M, Wellington M, Cardenas ME, Madhani HD, Heitman J, Krysan DJ (2014) Estrogen receptor antagonists are anti-cryptococcal agents that directly bind EF hand proteins and synergize with fluconazole in vivo. mBio 5(1):e00765-e00713. https://doi.org/10.1128/mBio.00765-13

24. Dyall J, Coleman CM, Hart BJ, Venkataraman T, Holbrook MR, Kindrachuk J, Johnson RF, Olinger GG Jr, Jahrling PB, Laidlaw M, Johansen LM, Lear-Rooney CM, Glass PJ, Hensley LE, Frieman MB (2014) Repurposing of clinically developed drugs for treatment of Middle East respiratory syndrome coronavirus infection. Antimicrob Agents Chemother 58(8):4885-4893. https://doi.org/ 10.1128/AAC.03036-14

25. Montoya MC, Krysan DJ (2018) Repurposing estrogen receptor antagonists for the treatment of infectious disease. mBio $9(6)$ : e02272-e02218. https://doi.org/10.1128/mBio.02272-18

26. Dompe.com. Press release. EU-supported private-public consortium Exscalate4CoV: raloxifene proposed for clinical trials after tests show it inhibits SARS-CoV-2. https:/www.dompe.com/en/ media/press-releases. Accessed 3 July 2020

27. Bukowska A, Spiller L, Wolke C, Lendeckel U, Weinert S, Hoffmann J, Bornfleth P, Kutschka I, Gardemann A, Isermann B, Goette A (2017) Protective regulation of the ACE2/ACE gene expression by estrogen in human atrial tissue from elderly men. Exp Biol Med (Maywood) 242(14):1412-1423. https://doi.org/10. $1177 / 1535370217718808$

28. Brosnihan KB, Hodgin JB, Smithies O, Maeda N, Gallagher P (2008) Tissue-specific regulation of ACE/ACE2 and AT1/AT2 
receptor gene expression by oestrogen in apolipoprotein E/ oestrogen receptor-alpha knock-out mice. Exp Physiol 93(5):658664. https://doi.org/10.1113/expphysiol.2007.041806

29. Suba Z (2020) Prevention and therapy of COVID-19 via exogenous estrogen treatment for both male and female patients. J Pharm Pharm Sci 23(1):75-85. https://doi.org/10.18433/jpps31069

30. Zhou Y, Vedantham P, Lu K, Agudelo J, Carrion R Jr, Nunneley JW, Barnard D, Pöhlmann S, McKerrow JH, Renslo AR, Simmons G (2015) Protease inhibitors targeting coronavirus and filovirus entry. Antivir Res 116:76-84. https://doi.org/10.1016/j.antiviral. 2015.01.011

31. Yamamoto M, Matsuyama S, Li X, Takeda M, Kawaguchi Y, Inoue JI, Matsuda Z (2016) Identification of nafamostat as a potent inhibitor of Middle East respiratory syndrome coronavirus S protein-mediated membrane fusion using the split-protein-based cell-cell fusion assay. Antimicrob Agents Chemother 60(11): 6532-6539. https://doi.org/10.1128/AAC.01043-16

32. Hoffmann M, Schroeder S, Kleine-Weber H, Müller MA, Drosten C, Pöhlmann S (2020) Nafamostat mesylate blocks activation of SARS-CoV-2: new treatment option for COVID-19. Antimicrob Agents Chemother AAC.00754-20. https://doi.org/10.1128/AAC. 00754-20

33. Clinckemalie L, Spans L, Dubois V, Laurent M, Helsen C, Joniau S, Claessens F (2013) Androgen regulation of the TMPRSS2 gene and the effect of a SNP in an androgen response element. Mol Endocrinol 27(12):2028-2040. https://doi.org/10.1210/me.20131098

34. Goren A, Vaño-Galván S, Wambier CG, McCoy J, Gomez-Zubiaur A, Moreno-Arrones OM, Shapiro J, Sinclair RD, Gold MH, Kovacevic M, Mesinkovska NA, Goldust M, Washenik K (2020) A preliminary observation: male pattern hair loss among hospitalized COVID-19 patients in Spain - a potential clue to the role of androgens in COVID-19 severity. J Cosmet Dermatol 19:15451547. https://doi.org/10.1111/jocd.13443

35. Montopoli M, Zumerle S, Vettor R, Rugge M, Zorzi M, Catapano CV, Carbone GM, Cavalli A, Pagano F, Ragazzi E, Prayer-Galetti $\mathrm{T}$, Alimonti A (2020) Androgen-deprivation therapies for prostate cancer and risk of infection by SARS-CoV-2: a population-based study (n=4532). Ann Oncol. https://doi.org/10.1016/j.annonc. 2020 . 04.479
36. Peters MC, Sajuthi S, Deford P, Christenson S, Rios CL, Montgomery MT, Woodruff PG, Mauger DT, Erzurum SC, Johansson MW, Denlinger LC, Jarjour NN, Castro M, Hastie AT, Moore W, Ortega VE, Bleecker ER, Wenzel SE, Israel E, Levy BD, Seibold MA, Fahy JV (2020) COVID-19-related genes in sputum cells in asthma. Relationship to demographic features and corticosteroids. Am J Respir Crit Care Med 202(1):83-90. https://doi.org/10.1164/rccm.202003-0821OC

37. Bradding P, Richardson M, Hinks TSC, Howarth PH, Choy DF, Arron JR, Wenzel SE, Siddiqui S (2020) ACE2, TMPRSS2, and furin gene expression in the airways of people with asthmaimplications for COVID-19. J Allergy Clin Immunol S00916749(20):30730-30732. https://doi.org/10.1016/j.jaci.2020.05.013

38. Recoverytrial.net. Low-cost dexamethasone reduces death by up to one third in hospitalised patients with severe respiratory complications of COVID-19. https://www.recoverytrial.net/news, published on June 16, 2020. Accessed 3 July 2020

39. Gooz M (2010) ADAM-17: the enzyme that does it all. Crit Rev Biochem Mol Biol 45(2):146-169. https://doi.org/10.3109/ 10409231003628015

40. Xu J, Mukerjee S, Silva-Alves CR, Carvalho-Galvão A, Cruz JC, Balarini CM, Braga VA, Lazartigues E, França-Silva MS (2016) A disintegrin and metalloprotease 17 in the cardiovascular and central nervous systems. Front Physiol 7:469. https://doi.org/10.3389/ fphys.2016.00469

41. Ren J, Nie Y, Lv M, Shen S, Tang R, Xu Y, Hou Y, Zhao S, Wang $\mathrm{T}$ (2015) Estrogen upregulates MICA/B expression in human nonsmall cell lung cancer through the regulation of ADAM17. Cell Mol Immunol 12(6):768-776. https://doi.org/10.1038/cmi.2014. 101

42. Kyula JN, Van Schaeybroeck S, Doherty J, Fenning CS, Longley DB, Johnston PG (2010) Chemotherapy-induced activation of ADAM-17: a novel mechanism of drug resistance in colorectal cancer. Clin Cancer Res 16(13):3378-3389. https://doi.org/10. 1158/1078-0432.CCR-10-0014

Publisher's note Springer Nature remains neutral with regard to jurisdictional claims in published maps and institutional affiliations. 